Article

\title{
Equilibria in DPPC-Diosgenin and DPPC-Diosgenin Acetate Bilayer Lipid Membranes: Interfacial Tension and Microelectrophoretic Studies
}

\author{
Katarzyna Karwowska, Ewelina Skrodzka, Joanna Kotyńska $\mathbb{D}^{\mathbb{D}}$ and Aneta D. Petelska * $\mathbb{D}$ \\ Faculty of Chemistry, University of Bialystok, K. Ciolkowskiego 1K, 15-245 Bialystok, Poland; \\ k.karwowska@uwb.edu.pl (K.K.); e_skrodzka@interia.pl (E.S.); joannak@uwb.edu.pl (J.K.) \\ * Correspondence: aneta@uwb.edu.pl
}

Received: 25 February 2020; Accepted: 3 April 2020; Published: 8 April 2020

\begin{abstract}
Interactions between components of model lipid membranes (spherical lipid bilayers and liposomes) are investigated here. Parameters characterizing equilibria in the 1,2-dipalmitoyl-snglycero-3-phosphocholine (DPPC)-diosgenin (Dio) and 1,2-dipalmitoyl-sn-glycero-3-phosphocholine (DPPC)-diosgenin acetate (DAc) membrane systems have been determined. The interfacial tension measurement of spherical lipid bilayers was based on the Young-Laplace's equation using a homemade computer-controlled device. We assume a 1:1 complex in the DPPC-Dio and DPPC-DAc membrane systems. The parameters $A_{3}^{-1}$, the surface concentration of lipid membranes formed from these complexes, $\gamma_{3}$, the interfacial tension of such membranes, and, $K$, the constant stability of these complexes were calculated. Microelectrophoresis was used for examinations of the surface charge density of lipid membranes. The values were obtained here from electrophoretic mobility data applying Smoluchowsky's equation. The effect of $\mathrm{pH}$ ( $\mathrm{pH}$ ranged of 2 to 10) on the electrolyte solution and the compositions of the membranes was analyzed. The obtained results indicate that the modification of DPPC membranes with both Dio and DAc causes changes in surface charge density values and shifts of the isoelectric point.
\end{abstract}

Keywords: interfacial tension; microelectrophoresis; lipid bilayer; liposomes; diosgenin; diosgenin acetate; DPPC; complex formation equilibria

\section{Introduction}

Biological membranes are necessary for living organisms because they provide a selective barrier of permeability, as well an environment for many processes occurring there [1]. These membranes are usually described as lipid bilayers, associated with proteins and other components, e.g., polysaccharides [2]. Currently, many studies are carried out on membrane models, i.e., monolayers [3] or bilayers [4-6]. The main goal of developing artificial lipid membranes is to reproduce the natural functions and to understand the interaction between all the membrane components on the molecular level [7]. Moreover, lipid membrane models are used in studies of drug transport through membranes [8] or in biosensors $[9,10]$.

Saponins belong to a group of biological active compounds. They are natural compounds that are present in many plants of various species [11]. Their sources include stems, leaves, and fruits, but also plant roots. In addition to plants, saponins are also components of fungi and marine organisms, such as starfish [12]. Saponins are high molecular weight glycosides, consisting of a polycyclic aglycone part (sapogenin) combined with one or more side chains of the sugar molecule [13]. Due to the structure of saponins, they are divided into two main groups, namely steroidal and triterpene [14]. Saponins have many interesting properties. One of them is the active property of lowering surface tension and foaming properties, as evidenced by the amphipathic nature of these substances. They are used in the 
cosmetics industry, in the laundry detergent industry, and the food industry [15]. However, the most valuable properties of saponins are their healing properties. They possess anti-inflammatory $[16,17]$, antimicrobial [18,19], and antifungal [20] properties, but are also used to synthesize steroid drugs or hormones. Literature reports also indicate that saponin compounds have antitumor activity [21]. Modern research proves that saponins can inhibit the growth of various cancer cells by inhibiting the cell cycle and apoptosis [22].

Due to their high biological and pharmacological activity and amphiphilic character, saponins are widely used by scientists as lipid membrane components [23-26]. Korchowiec et al., using Langmuir monolayer techniques, studied the interaction between saponins (digitonin and the commercial Merck Saponin) and lipid model systems. The authors concluded that the saponins influence lipid membranes by changing the physical state of membranes [23]. Geisler et al. discussed recent progress in the physicochemical understanding of interactions between $\beta$-aescin and phospholipid model membranes [26]. The results summarized in the review indicate that the interactions are due to the specific molecular structure of $\beta$-aescin. In particular, the $\mathrm{pH}$ and the protonation state of studied saponin, affect its self-assembly in lipid membranes [26].

The compounds that are the subject of this study (diosgenin and diosgenin acetate) are classified as steroid sapogenins, i.e., only non-sugar parts of saponins are studied here. According to the literature cited above, many studies exist on the therapeutic effects of saponins, but the properties of sapogenins themselves have not been studied yet. Diosgenin and diosgenin acetate were chosen here due to their many treatment properties, in particular, their cytotoxic activity to cancer cells. The literature data show that diosgenin inhibits proliferation and induces apoptosis in various cancer cells, such as, colon carcinoma, breast carcinoma cells, and leukemia [27-29].

According to our knowledge, there are few data on interactions between bilayer lipid membranes and sapogenin; in particular, there is a lack of data concerning the physicochemical and electrical properties of bilayer lipid membranes when modified by diosgenin and diosgenin acetate. Therefore, this work aims to analyze the impact of these sapogenins on the interfacial tension and the surface charge density of the model cell membranes (spherical bilayer lipid membranes and liposomes, Figure 1). These parameters are very important for characterizing lipid membranes, both natural and artificial membranes. We previously described changes in the interfacial tension and the surface charge density influenced by, for example, membrane compositions in lipid-lipid [30-32], lipid-sterol [33,34], and lipid-fatty acid [35], or lipid-amine membranes [36,37]. Particularly important for understanding the membrane surface phenomena is their quantitative assessment, which is necessary for the complete interpretation. We realize this here by using simple mathematical relationships for the theoretical models relating to the quantitative description of phenomena between the membrane components and between them and surroundings. Then, through theoretical descriptions of complex formation, we can verify the experimental and theoretical data. This enables the quantitative determination of the parameters describing the equilibria, i.e., the surface tension, surface pressure, surface charge density, stability constants, and complex formation energies. Since no accurate data of the stability constants for forming connections exist in the literature, our team, as a first, has determined these parameters and introduced them to the world. This represents an original contribution to the knowledge of the biochemistry and biophysics of lipid membranes [30-37].

The examinations presented in this paper are a continuation of our research on the interaction of model membranes (1,2-dipalmitoyl-sn-glycero-3-phosphocholine) and molecules of increasing complexity (diosgenin, diosgenin acetate). We analyze the effect of interfacial tension on the composition of the 1,2-dipalmitoyl-sn-glycero-3-phosphocholine (DPPC)-Dio and DPPC-DAc systems over a possible range of compositions. We also show a comparison of the complexes' parameters (stability constants and the surface areas). We also analyze the effect of the $\mathrm{pH}$ of the electrolyte solution and the compositions of the membranes on surface charge to better describe interactions in the DPPC membranes when modified by the sapogenins. Since these parameters influence the interactions between the membranes and biological active compounds, the data presented below may be, in our opinion, useful in understanding membrane binding mechanisms. 




(a)

(b)

Figure 1. (a) Spherical lipid membrane and (b) liposome.

\section{Materials and Methods}

\subsection{Materials}

Membrane-forming materials: 1,2-Dipalmitoyl-sn-glycero-3-phosphocholine (semisynthetic, $\geq 99 \%$ ), diosgenin (>99\%, TLC), and diosgenin acetate (>98.5\%) were purchased and used as received (Table 1). DPPC bilayers exhibit a well-defined gel phase at a measurement temperature of $293 \mathrm{~K}$. The molecular weights of DPPC, Dio, and DAc were approximately determined to be 734.04, 414.62, and $456.67 \mathrm{~g} \cdot \mathrm{mol}^{-1}$, respectively.

Table 1. Reagents used in experiments.

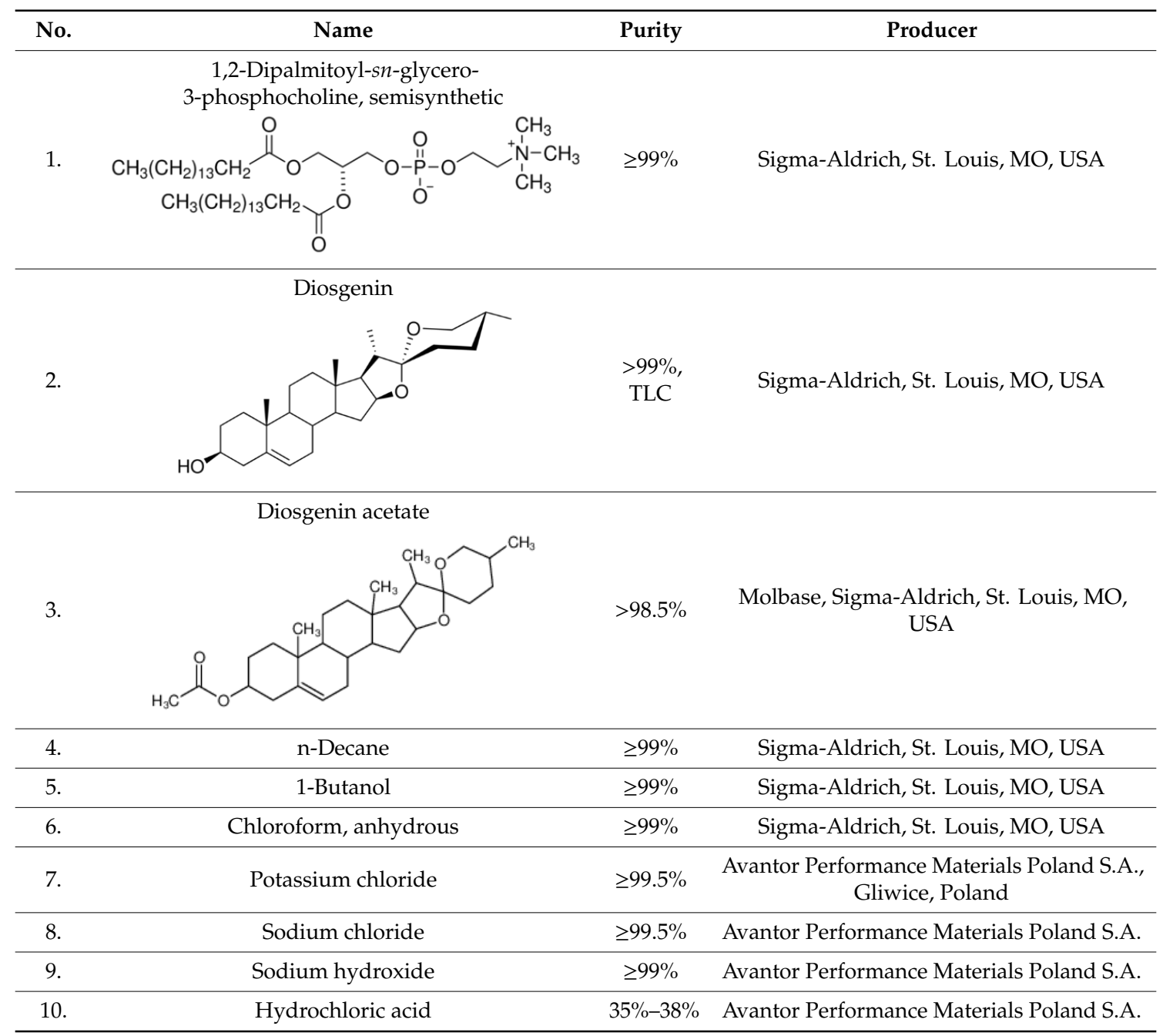

Electrolyte solutions: The electrolyte solutions for interfacial tension measurements $(0.1 \mathrm{M}$ potassium chloride) and microelectrophoretic measurements ( $0.155 \mathrm{M}$ sodium chloride) were prepared 
using water purified through a Milli-Q plus water purification system (Millipore, Burlington, MA, USA) with a resistivity of $18.2 \mathrm{M} \Omega \cdot \mathrm{cm}$.

The characteristics of the reagents used for the research are presented in Table 1.

\subsubsection{Spherical Bilayers Preparation}

Spherical bilayer-forming solutions: DPPC, Dio, and DAc were purified by dissolving in chloroform (anhydrous, $\geq 99 \%$ ), then the solvent was evaporated under inert gas. The stock solutions for bilayer formation were composed of $20 \mathrm{mg} \cdot \mathrm{cm}^{-3}$ of the tested components (DPPC, Dio, DAc) in $\mathrm{n}$-decane and butanol (anhydrous, $\geq 99 \%$ ) in a ratio of 20:1. The solution containing the membrane components was stored at $4{ }^{\circ} \mathrm{C}$. During bilayer formation, the organic solvents were removed and the membrane composition is the same proportion as the tested components as in the stock solution.

\subsubsection{Liposomes Preparation}

Liposomes-forming solutions: The solutions for liposome formation were composed of $10 \mathrm{mg} \cdot \mathrm{cm}^{-3}$ of the tested substances (DPPC, Dio, or DAc) in n-chloroform (anhydrous, $\geq 99 \%$ ) were mixed in various molar ratios $(3: 1 ; 1: 1 ; 1: 3)$. Then, the n-chloroform was evaporated under a stream of inert gas to obtain a dry residue. The resulting residue was hydrated with an electrolyte solution $(0.155 \mathrm{M} \mathrm{NaCl})$.

Preparation of liposomes via the sonication method: The lipid membranes were prepared by sonicating the suspension (ultrasound generator UD 20, Techpan, Poland). The operation was repeated five times, $90 \mathrm{~s}$ each. It was carried out using an ice bath, since, during the process, heat is liberated.

\subsection{Interfacial Tension Measurements}

Working conditions and experimental procedure: The interfacial tension measurements are based on Young's and Laplace's equation [38]:

$$
2 \gamma=R \Delta p
$$

Using the equation, it is possible to determine the interfacial tension, $\gamma$, of a lipid bilayer by measuring the radius of curvature, $R$, of a convex surface formed by pressure difference, $\Delta p$, applied on both sides.

The apparatus and method of measurement have both been described in detail previously [39-41]. The measurement cell is built of two glass elements separated by a mount holding $(0.15 \mathrm{~cm}$ diameter $)$ circular Teflon cap that has been axially pierced, leaving a small orifice. The Mueller-Rudin method [42] was used to form the bilayers at the flat end of the Teflon cap. Both glass elements were filled with $0.1 \mathrm{M} \mathrm{KCl}$. The stock solution was introduced into the flat wall of the Teflon cap, and the pressure was applied to the left glass element of the measuring cell using a manometer.

The convexity of the bilayer cap was measured to a $0.05-\mathrm{mm}$ precision by the optical part of the measuring apparatus consisting of a charge-coupled device (CCD) camera and monitor. The convexity of the bilayers was monitored using reflected light microscopy with a high-brightness yellow LED source. The microscope and LED were mounted on brackets, enabling the illuminator, measuring vessel, and microscope to be placed on the optical axis. The distance between the microscope and the measuring cell can also be adjusted to focus on the membrane deep in the measuring vessel. Then, the radius of curvature was determined using the convexity obtained values of the lipid cap and the diameter of the Teflon element on which the membranes were formed, corresponding to the diameter of the lipid cap.

The radius of curvature, $R$, was obtained using this value and the diameter of the Teflon cap, $r$, corresponding to the diameter of the lipid cap and the convexity of the bilayer, as shown in Figure 2 .

The overpressure, $\Delta p$, causing the bilayer convexity was determined using the manometer. The radius of the curvature of the membrane was measured using the optical part of the measuring cell. Then, the interfacial tension according to Young's and Laplace's equation (from the radius of curvature and pressure difference) was calculated. 


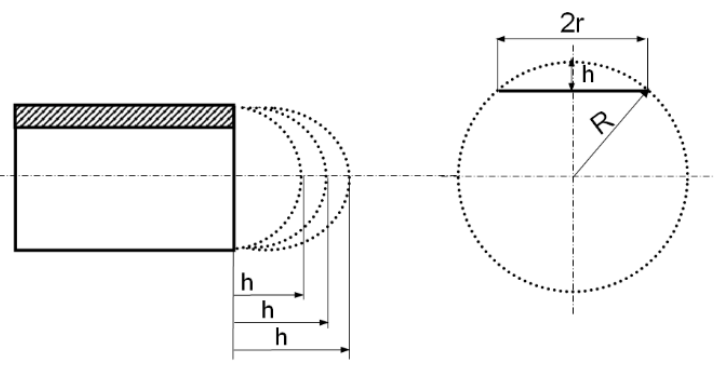

Figure 2. Scheme presenting the determination of the radius of curvature. $R$ is radius of curvature, $r$ is radius of the Teflon cap, $h$ is the convexity of the bilayer. The radius of curvature was calculated as $R=r^{2}+h^{2} / 2 h$.

The interfacial tension was measured on a bilayer 12-15 times. For each bilayer, about 10 instrument readings of the lipid spherical cap diameter were made, where the cap is formed by the pressure difference applied on both sides. These measurements were made within the whole range, from the very low values of the lipid spherical cap diameter to those almost equal to the Teflon cap radius. From all of the instrument readings, the arithmetical means and standard deviations were enumerated. Measurements with the preparation of the electrolyte solution were made 2-3 times to test the repeatability of these determinations. All presented experiments were carried out at a temperature of $293 \pm 2 \mathrm{~K}$.

\subsection{Microelectrophoretic Measurements}

The electrophoretic mobility values of liposomes were obtained using the laser Doppler Micro-electrophoresis (LDE) technique with a high performance Zetasizer Nano ZS (Malvern Instruments, Malvern, UK) analyzer. All measurements were performed vs. pH using a WTW InoLab pH 720 laboratory meter (WTW, Weinheim, Germany). Liposomes suspended in the electrolyte solution $\left(0.155 \mathrm{~mol} \cdot \mathrm{dm}^{-3} \mathrm{NaCl}\right)$ were titrated to the given $\mathrm{pH}$ (range 2-10, every \pm 0.3 units) with hydrochloric acid or sodium hydroxide. Six measurements were performed (each consisting of 100-200 runs, duration of $5 \mathrm{~s}$ ) for each $\mathrm{pH}$ value, for each sample. The experiments were performed three times. The membrane surface charge densities were calculated with help presented below equation from the electrophoretic mobility data [43]:

$$
\delta=\frac{\eta \cdot u}{d}
$$

where $u$ is the electrophoretic mobility, $\eta$ is the viscosity of solution, and $d$ is the thickness of the diffuse layer.

\section{Results and Discussion}

The problem of understanding the influence of biological active substances on the physicochemical properties of cell membranes is extremely important, in view of many possible applications in membrane science, such as the interaction of significant biological activity molecules with cell membranes. Various studies carried out in the past few years have confirmed the strong potential of bioactive compounds to inhibit the growth of various cancer cells. However, in the literature, there are few data on the effect of these substances on the electrical and physicochemical properties of model systems, where the lack of quantitative descriptions of equilibria is noticeable.

\subsection{Interfacial Tension Experiment and Theoretical Considerations}

We have considered the case when the components of the lipid bilayer of a two-component membrane, e.g., DPPC (component 1 ) and diosgenin or diosgenin acetate (component 2), do not form chemical compounds, where the interactions between the membrane components can then be described [30,41]: 


$$
\begin{gathered}
\gamma_{1} m_{1} A_{1}+\gamma_{2} m_{2} A_{2}=\gamma \\
\frac{m_{1}}{m_{1}+m_{2}}=x_{1} \\
x_{1}+x_{2}=1
\end{gathered}
$$

where $A_{1}^{-1}$ and $A_{2}^{-1}\left(\mathrm{~mol} \cdot \mathrm{m}^{-2}\right)$ are the surface concentrations of bilayer components 1 and $2, m_{1}$ and $m_{2}$ $\left(\mathrm{mol} \cdot \mathrm{m}^{-2}\right)$ are the quantities of bilayer components 1 and 2 per unit area of the membrane, $\gamma_{1}$ and $\gamma_{2}$ $\left(\mathrm{N} \cdot \mathrm{m}^{-1}\right)$ are the interfacial tensions of membranes formed from pure components 1 and $2, \gamma\left(\mathrm{N} \cdot \mathrm{m}^{-1}\right)$ is the measured interfacial tension of the bilayer membrane, and $x_{1}$ and $x_{2}$ are the solution mole fractions of bilayer components 1 and 2 .

A linear equation is obtained by elimination of parameters $m_{1}$ and $m_{2}$ :

$$
\left(\gamma-\gamma_{1}\right) x_{1}=\frac{A_{2}}{A_{1}}\left(\gamma_{2}-\gamma\right) x_{2}
$$

The membranes can also make the two elements able to form a complex. Complex stoichiometry results may vary, but since the first stability constant in these complexes is usually the largest [44], we assumed that the complexes primarily have 1:1 stoichiometry.

In cases where membrane components form a 1:1 complex, interactions in the membrane can be described using a previously published set of equations [45]. The equilibrium between the individual components that make up the complex can be written as follows:

$$
\begin{array}{cccc}
\mathrm{A} & \mathrm{B} & \Leftrightarrow & \mathrm{AB} \\
\text { (Component 1) } & \text { (Component 2) } & \text { (Complex) }
\end{array}
$$

Thus, the basic equation describing the interaction between components 1 and 2 can be written as follows:

$$
\begin{gathered}
{\left[\left(\gamma-\gamma_{1}\right) B_{2} x_{1}+\left(\gamma-\gamma_{2}\right) B_{1} x_{2}\right]\left[\left(\gamma_{3}-\gamma_{1}\right) B_{2} x_{1}+\left(\gamma_{3}-\gamma_{2}\right) B_{1} x_{2}+\left(\gamma_{1}-\gamma_{2}\right)\left(x_{1}-x_{2}\right)\right]} \\
=K A_{3}^{-1} B_{1} B_{2}\left[\left(\gamma-\gamma_{1}\right)\left(x_{2}-x_{1}\right)+\left(\gamma_{3}-\gamma\right) B_{1} x_{2}\right]\left[\left(\gamma-\gamma_{2}\right)\left(x_{1}-x_{2}\right)+\left(\gamma_{3}-\gamma\right) B_{2} x_{1}\right]
\end{gathered}
$$

where $B_{1}=\frac{A_{3}}{A_{1}}$ and $B_{2}=\frac{A_{3}}{A_{2}}$.

Equation (8) can be simplified, assuming that the stability constant of the resulting complex has a high value. The use of this simplification results in linear behavior for small $\left(x_{2}<x_{1}\right)$ and large $\left(x_{2}>x_{1}\right) x_{2}$ values.

$$
\begin{aligned}
& \left(\gamma_{1}-\gamma\right) \frac{x_{1}-x_{2}}{x_{2}}=-B_{1} \gamma_{3}+B_{1} \\
& \left(\gamma_{2}-\gamma\right) \frac{x_{2}-x_{1}}{x_{1}}=-B_{2} \gamma_{3}+B_{2}
\end{aligned}
$$

When calculating the stability constant for the complex, Equation (8) can be simplified to $x_{1}=x_{2}$.

$$
\begin{aligned}
& K\left(A_{1}^{-1}\right)^{2}\left(A_{2}^{-1}\right)^{2}\left(A_{3}^{-1}\right)^{-1}\left(\gamma-\gamma_{3}\right)^{2} \\
& =\left[\gamma_{2} A_{1}^{-1}+\gamma_{1} A_{2}^{-1}-\gamma\left(A_{1}^{-1}+A_{2}^{-1}\right)\right]\left(\gamma_{2} A_{1}^{-1}+\gamma_{1} A_{2}^{-1}\right) \\
& -\left[\gamma_{2} A_{1}^{-1}+\gamma_{1} A_{2}^{-1}-\gamma\left(A_{1}^{-1}+A_{2}^{-1}\right)\right]\left(A_{1}^{-1}+A_{2}^{-1}\right) \gamma_{3}
\end{aligned}
$$

Equation (12) is used to calculate theoretical interfacial tension values for agreement between experimental and theoretical data.

$$
\begin{aligned}
& K A_{1}^{-1} A_{2}^{-1}\left(a_{1}+a_{2}\right)\left(a_{3}-a_{1}\right) \gamma^{2} \\
& +\left[K A_{1}^{-1} A_{2}^{-1}\left(\gamma_{1} a_{1}-\gamma_{3} a_{3}\right)\left(a_{1}+a_{2}\right)-K A_{1}^{-1} A_{2}^{-1}\left(\gamma_{2} a_{1}+\gamma_{3} a_{2}\right)\left(a_{3}-a_{1}\right)+a_{4} A_{3}^{-1}\left(a_{3}+a_{2}\right)\right] \gamma \\
& +K A_{1}^{-1} A_{2}^{-1} a_{3} \gamma_{3}\left(\gamma_{3} a_{2}+\gamma_{1} a_{2}\right)-K A_{1}^{-1} A_{2}^{-1} a_{1} \gamma_{1}\left(a_{1} \gamma_{2}+a_{2} \gamma_{3}\right)-a_{4} A_{3}^{-1}\left(\gamma_{2} a_{3}+\gamma_{1} a_{2}\right)=0
\end{aligned}
$$


where:

$$
\begin{aligned}
& a_{1}=A_{3}^{-1}\left(x_{2}-x_{1}\right) \\
& a_{2}=A_{2}^{-1} x_{1} \\
& a_{3}=A_{1}^{-1} x_{2} \\
& a_{4}=\left[A_{3}^{-1}\left(\gamma_{1}-\gamma_{2}\right)\left(x_{2}-x_{1}\right)+\left(\gamma_{1}-\gamma_{3}\right) x_{1} A_{2}^{-1}+\left(\gamma_{2}-\gamma_{3}\right) x_{2} A_{1}^{-1}\right]
\end{aligned}
$$

In the case of the two-component systems, it was assumed that the formation of a 1:1 complex is an explanation of the deviation from the additivity rule. Theoretical curves were obtained using the parameters characterizing complexes, such as the stability constants, molecular areas, and interfacial tension values. The accuracy of the presented models was verified by comparison with experimental data.

The complex formation energy of the DPPC-Dio and DPPC-DAc systems was calculated by Equation (13):

$$
-\log K=\frac{\Delta G^{0}}{2.3 R T}
$$

where $K\left(\mathrm{~m}^{2} \cdot \mathrm{mol}^{-1}\right)$ is the stability constant of the DPPC-Dio or DPPC-DAc complex, $\Delta G^{0}\left(\mathrm{~J} \cdot \mathrm{mol}^{-1}\right)$ is the DPPC-Dio or DPPC-DAc complex formation energy, $R\left(\mathrm{~J} \cdot \mathrm{mol}^{-1} \cdot \mathrm{K}^{-1}\right)$ is the gas constant, and $T(\mathrm{~K})$ is the temperature in Kelvin.

Figure 3 contains graphs for two systems, namely the DPPC-Dio (Figure 3a) and DPPC-DAc (Figure $3 b$ ) systems. When there are no interactions between membrane components, these functions should give straight lines (Equation (2)). Of course, this is not the case, suggesting that there is a complex or different structure in the DPPC-Dio and DPPC-DAc systems. Since Equation (3) assumes the formation of a 1:1 complex, our initial assumption was that, between the components of the bilayer, they form a complex. The interfacial tension of the examined systems was analyzed over the entire possible range of components' compositions.

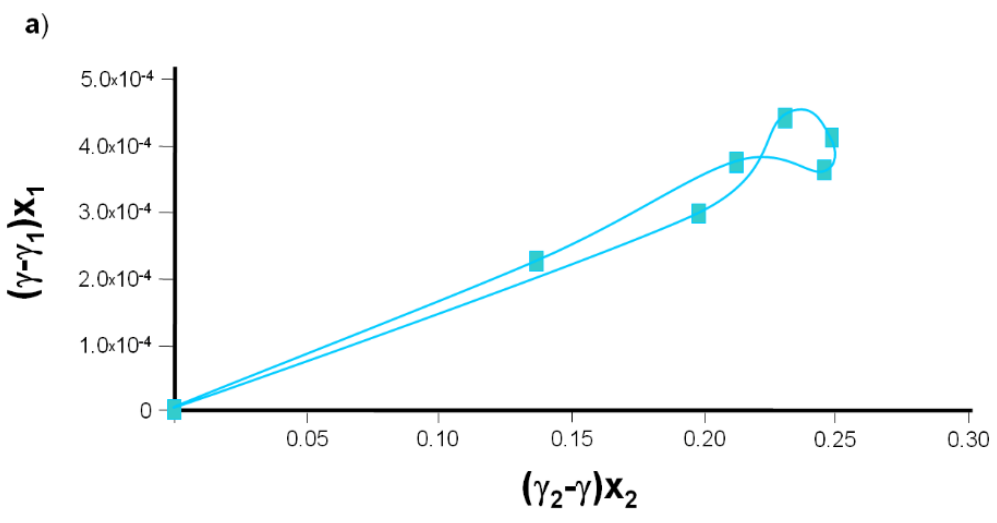

b)

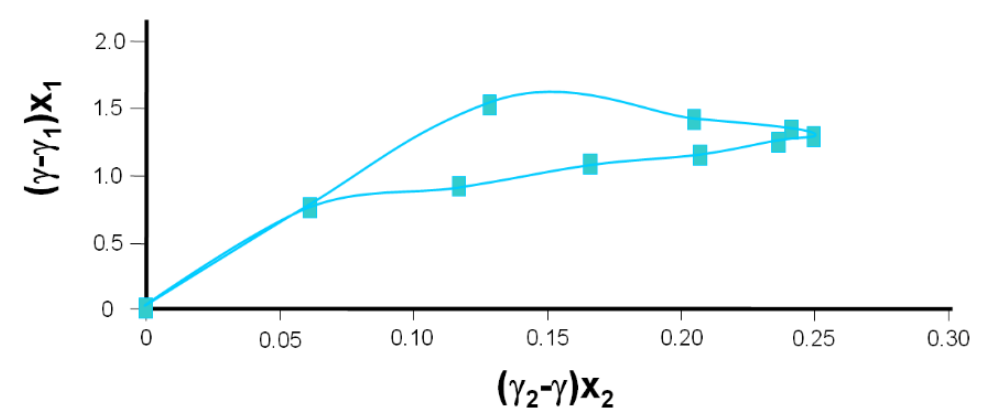

Figure 3. Plot of Equation (2) for DPPC-Dio (a) and DPPC-DAc (b), where $x_{1}$ and $x_{2}$ are the mole fractions of components 1 and 2 (DPPC and Dio or DAc, respectively), showing interfacial tension measurements. DPPC: 2-Dipalmitoyl-sn-glycero-3-phosphocholine. Dio: Diosgenin. DAc: Diosgenin acetate. 


\subsubsection{DPPC-Diosgenin Complex}

The dependence of bilayer interfacial tension vs. membrane composition for the DPPC-Dio and DPPC-DAc membrane was analyzed in the possible concentration range. The interfacial tension of the DPPC-Dio membrane was determined vs. the composition with $60 \%$ of the diosgenin content because only with such contents of component 2 (Dio) with DPPC was a bilayer created. The pure DPPC interfacial tension value (component 1$), \gamma_{1}$, was determined directly and presented [45], equal to $1.62 \pm 0.12 \times 10^{-3} \mathrm{~N} \cdot \mathrm{m}^{-1}$. Since diosgenin (component 2) does not create a bilayer, there are no accurate interfacial tension data in the literature. To describe the course of the experimental plot, the $\gamma_{2}$ value for the pure component is necessary. Therefore, the hypothetical interfacial tension data for the Dio bilayer were calculated by adjusting the experimental curve with the polynomial of the other mark, extrapolating the $x_{2}=1$ value (Figure 4). The value is equal to $6.33 \times 10^{-4} \mathrm{~N} \cdot \mathrm{m}^{-1}$. Such a low interfacial tension value confirms that it is not possible to create a pure Dio bilayer.

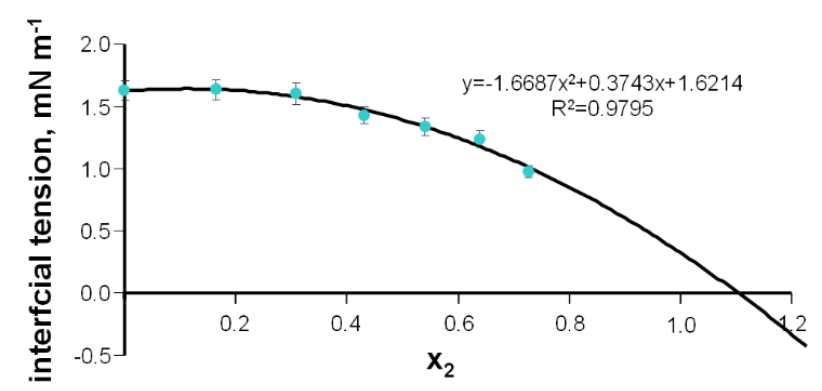

Figure 4. Hypothetical interfacial tension data for diosgenin bilayer.

Figure 5 a illustrates the interfacial tension of a DPPC-Dio bilayer vs. the mole fraction of diosgenin. The interfacial tension values of the pure DPPC and pure Dio bilayers are $1.62 \times 10^{-3}$ and $0.33 \times$ $10^{-3} \mathrm{~N} \cdot \mathrm{m}^{-1}$, respectively.
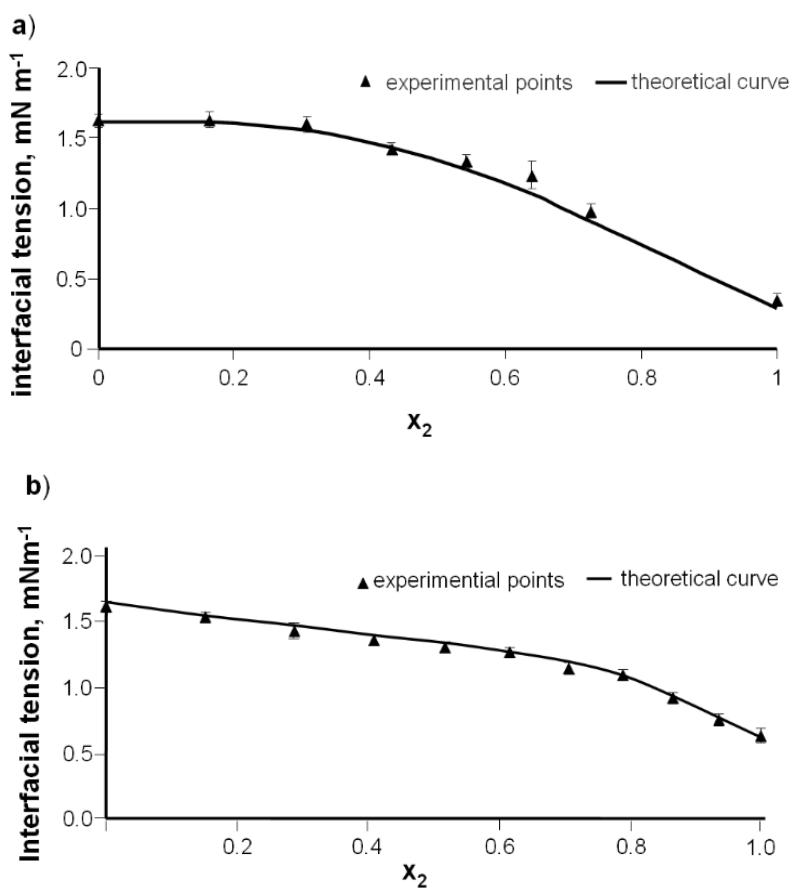

Figure 5. DPPC-diosgenin (a), and DPPC-diosgenin acetate (b) interfacial tension values vs. mole fraction $x_{2}$ (component 2 ); the theoretical values are marked by curves and the experimental values by points. 
When there are no interactions, the curve presented in Figure 3a should be a straight line (Equation (6)). The nonlinear nature of the graph indicates the interaction between DPPC and diosgenin. Such interactions may be explained by the complex formation [46-48]. Petelska and co-workers [47] demonstrated the formation of a 1:1 complex in the DPPC-diosgenin in a monolayer system with a high value for the stability constant. This suggests that these types of complexes may also be formed by the components of the lipid bilayers.

According to the literature data, the 1:1 complex (termed compound 3) creates the most stable structure with a maximal stability constant, K [44]. The dependence of interfacial tension vs. the stock solution composition (assumption of 1:1 complex formation) is described by Equation (8). The interfacial tensions of the pure components' bilayers were obtained in an experimental way. The constants $B_{1}, B_{2}$, and $\gamma_{3}$ were calculated by assuming that the value of the stability constant for the DPPC-Dio complex was sufficient for the simplified Equation (8) to be applied to Equations (9) and (10).

The plots of Equations (9) and (10) are illustrated in Figure 6a. From the slopes of the lines, $B_{1}$ (3.631) and $B_{2}$ (1.028) values were obtained. The intersections of the straight lines with the ordinate provide $-B_{1} \gamma_{3}$ and $-B_{2} \gamma_{3}$, which can be used to determine $\gamma_{3}$, the interfacial tension of the DPPC-Dio complex. The mean value obtained in this way was $1.37 \times 10^{-3} \mathrm{~N} \cdot \mathrm{m}^{-1}$.

a)
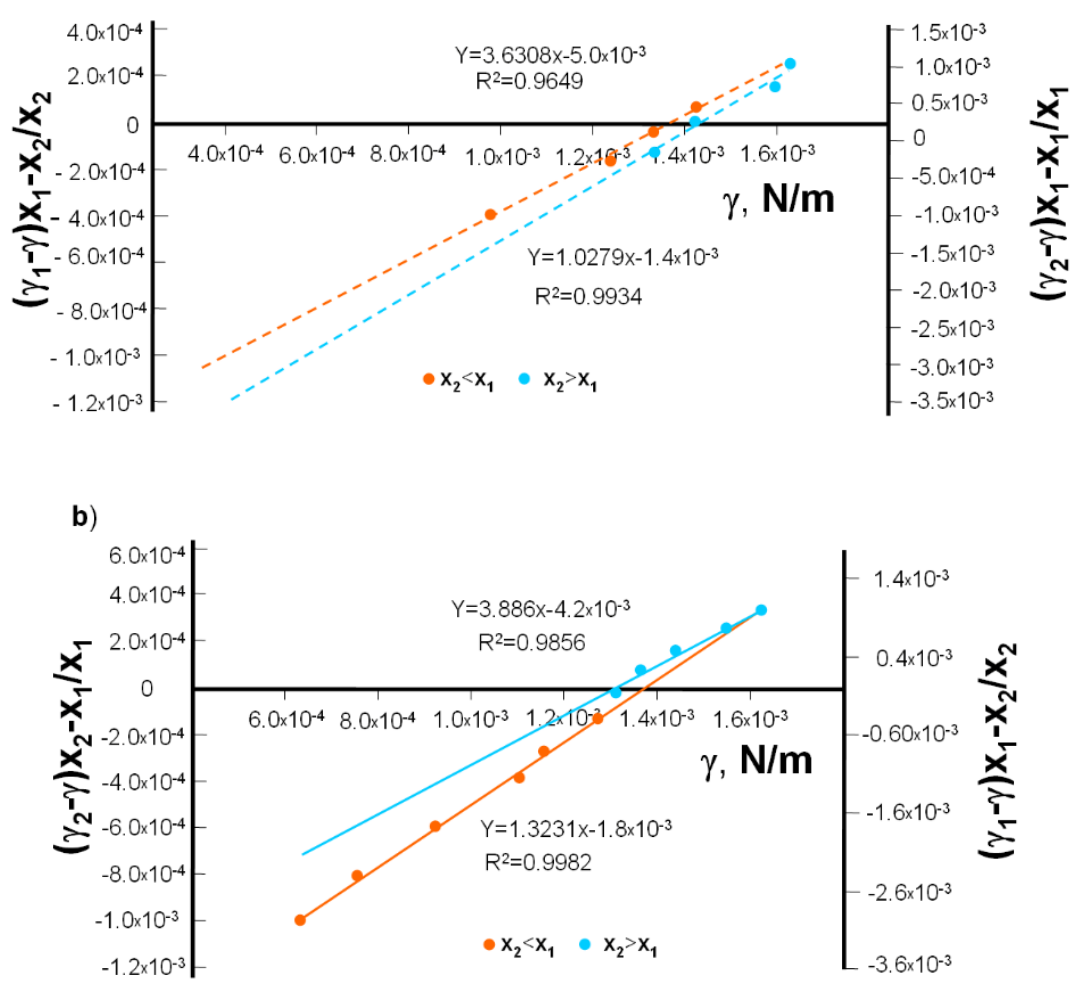

Figure 6. Graph showing Equations (9) and (10) for determining $B_{1}, B_{2}$, and $\gamma$ : parameters: (a) the DPPC-diosgenin system and $(\mathbf{b})$ the DPPC-diosgenin acetate system.

Determining the interfacial tension as a function of the composition enabled the calculation of the surface concentrations for bilayers formed of DPPC and Dio. At least one of these calculations is necessary to determine the value of $A_{3}^{-1}$. The surface areas occupied by DPPC and diosgenin are $85.0 \pm$ 0.9 [30] and $45 \pm 0.5 \AA^{2}$. molecule ${ }^{-1}$ [47], respectively.

The surface concentrations of DPPC and diosgenin in bilayers are $2.21 \times 10^{-6}$ and $3.69 \times$ $10^{-6} \mathrm{~mol} \cdot \mathrm{m}^{-2}$, respectively. Knowledge of $A_{1}^{-1}$ and $A_{2}^{-1}$ as well as $B_{1}$ and $B_{2}$ is needed to determine the surface concentration of a membrane composed of a DPPC-Dio complex. The obtained value, $A_{3}^{-1}$, for the DPPC-Dio complex was $1.11 \times 10^{-6} \mathrm{~mol} \cdot \mathrm{m}^{-2}$. Based on this, one can determine that the area 
occupied by one DPPC-Dio complex is approximately $150 \AA^{2} \cdot$ molecule ${ }^{-1}$. The value is larger than the sum of the areas occupied by individual DPPC and diosgenin molecules.

Using Equation (11), the stability constant of the DPPC-diosgenin complex was obtained by setting $x_{1}=x_{2}=0.5$ and the value was $1.11 \times 10^{7} \mathrm{~m}^{2} \cdot \mathrm{mol}^{-1}$. To our knowledge, no stability constants for the DPPC-Dio and DPPC-DAc complexes have been reported to date.

Based on the fact that the obtained value is relatively high, we can conclude that the 1:1 complex in mixed DPPC-diosgenin bilayers was formed. The $K$ value obtained for DPPC-Dio monolayers $\left(6.46 \times 10^{5} \mathrm{~m}^{2} \cdot \mathrm{mol}^{-1}\right)$ is about two orders of magnitude smaller than the $K$ values for bilayers [47]. The difference between these values is relatively large if we consider their different spatial surroundings. The higher value of the complex stability constant for the bilayer (about two orders of magnitude) may be a consequence of the roughness between the hydrophobic layers in the bilayer [49]. The complex present in the bilayer is thus additionally strengthened by interactions between the two layers of the bilayer.

\subsubsection{DPPC-Diosgenin Acetate Complex}

The dependence of bilayer interfacial tension vs. the composition of the DPPC-DAc was analyzed over a wide concentration range (Figure $5 b$ ).

According to Equation (6), the plot of Figure $3 b$ should yield a straight line. It can be seen from Figure $1 \mathrm{~b}$ that such linear dependences are not obtained. The curve indicates that the DPPC-diosgenin system forms a complex. The interfacial tensions of membranes formed using pure components were measured directly. The pure diosgenin acetate membrane exhibited an interfacial tension of $0.63 \pm 0.03$ $\times 10^{-3} \mathrm{~N} \cdot \mathrm{m}^{-1}$.

The value of $\gamma_{3}$ for the DPPC-DAc complex was calculated using Equations (9) and (10), presented in Figure 6b. The values of $B_{1}$ (3.189) and $B_{2}$ (1.623) were determined from the slopes of the lines. The intersections of the straight lines with the ordinate provide $-B_{1} \gamma_{3}$ and $-B_{2} \gamma_{3}$, which can be used to determine $\gamma_{3}$, the interfacial tension of the DPPC-Dio complex. The mean value obtained in this way was $1.34 \times 10^{-3} \mathrm{~N} \cdot \mathrm{m}^{-1}$.

Equations (9) and (10) could also be used to calculate the surface concentration per unit area of the membrane formed entirely from the DPPC-DAc complex (the surface area occupied by a diosgenin acetate molecule is $52 \pm 0.5 \AA^{2}$ [48] and the surface concentration calculated for a pure DAc membrane is $3.19 \times 10^{-6} \mathrm{~mol} \cdot \mathrm{m}^{-2}$ ).

The surface concentration for the DPPC-DAc complex is $1.19 \times 10^{-6} \mathrm{~mol} \cdot \mathrm{m}^{-2}$. From this value, it is possible to determine the area occupied by the DPPC-DAc complex, which is $135 \AA^{2} \cdot$ molecule $^{-1}$. The stability constant of the DPPC-DAc complex was determined using Equation (11). The stability constant is equal to $2.22 \times 10^{5} \mathrm{~m}^{2} \cdot \mathrm{mol}^{-1}$.

Calculated from Equation (13), the complex formation energy (Gibbs free energy) values for the DPPC-Dio and DPPC-DAc complexes were equal to $-39.74 \pm 1.05$ and $-30.16 \pm 0.91 \mathrm{~kJ} \cdot \mathrm{mol}^{-1}$, respectively. Table 2 presents some physicochemical values for DPPC-Dio and DPPC-DAc complexes.

Table 2. Some physicochemical values for the obtained complexes.

\begin{tabular}{|c|c|c|c|}
\hline $\begin{array}{l}\text { Studied } \\
\text { System }\end{array}$ & $\begin{array}{c}\text { Surface Area Occupied by } \\
\text { One Molecule of Complex } \\
{\left[\AA^{2} \cdot \text { molecule }^{-1}\right]}\end{array}$ & $\begin{array}{l}\text { Stability Constant of } \\
\text { Studied Complex } \\
{\left[\mathrm{m}^{2} \cdot \mathrm{mol}^{-1}\right]}\end{array}$ & $\begin{array}{c}\text { Complex Formation Energy } \\
\text { (Gibbs Free Energy) } \\
{\left[\mathrm{kJ} \cdot \mathrm{mol}^{-1}\right]}\end{array}$ \\
\hline DPPC-Dio & $150.0 \pm 1.5$ & $1.11 \times 10^{7}$ & $-39.74 \pm 1.05$ \\
\hline DPPC-DAc & $135.0 \pm 1.4$ & $2.22 \times 10^{5}$ & $-30.16 \pm 0.91$ \\
\hline
\end{tabular}

Standard uncertainties: $u(\mathrm{~A})=1.45 \AA^{2} \cdot$ molecule $^{-1}, u\left(\Delta G^{0}\right)=1.03 \mathrm{~kJ} \cdot \mathrm{mol}^{-1}$.

The theoretical data (obtained from Equation (12)) denoted by lines and the experimental ones denoted by points are illustrated in Figure 5a,b. From good agreement between theoretical and experimental data, it can be concluded that 1:1 DPPC-Dio and DPPC-DAc complexes are formed in bilayer membranes. 
The proposed models of the spherical lipid bilayer organization of DPPC-sapogenin and DPPC-cholesterol are shown in Figure 7. Both sapogenin and cholesterol in the bilayer do not influence the orientation of the lipid heads since the molecules are located in parallel with the DPPC chains and their hydroxyl groups are oriented at the level of the lipid's carbonyl groups (Figure 7). The stability constant values obtained for the DPPC-sapogenin 1:1 complex have a similar order of magnitude $\left(\sim 10^{6}-10^{7}\right)$ to the DPPC-cholesterol 1:1 complex $[45,50]$.

(a) DPPC - sapogenin

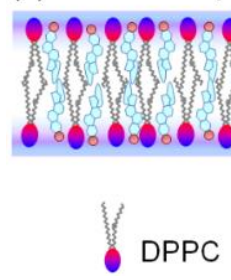

(b) DPPC - cholesterol

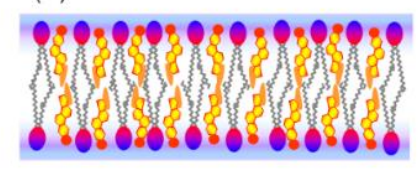

Figure 7. Proposed models of the lipid bilayer organization of DPPC-sapogenin (a) and DPPC-cholesterol (b) complexes.

\subsection{Microelectrophoretic Experiments}

The surface charge density of a lipid membrane is a significant parameter that controls some processes in natural cells. The surface charge is dependent on the molecular composition of the biological membrane and plays an important role in understanding membrane-binding mechanisms, cellular uptake, drug delivery, or liposome design. The parameter is an important property of a cell; it is useful in comparing the surface properties between two cell types [51,52].

Surface charge density changes in a living cell can occur commonly, including when they accompany the malignant transformation of cells. Since, membrane surface charge is influenced by many different factors, e.g., $\mathrm{pH}$ and membrane composition, its values can also be changed in vitro. This fact significantly contributes to the extension of cognitive capabilities, because in vitro studies of biological membranes and their artificial models are a valuable source of information on in vivo processes.

The effect of the sapogenins on the surface charge density of DPPC membranes was studied. The surface charge densities of DPPC-Dio and DPPC-DAc systems were drawn vs. $\mathrm{pH}$ (ranging from 2 to 10) and the molar composition of the components in the membranes (Figures 8 and 9, respectively).

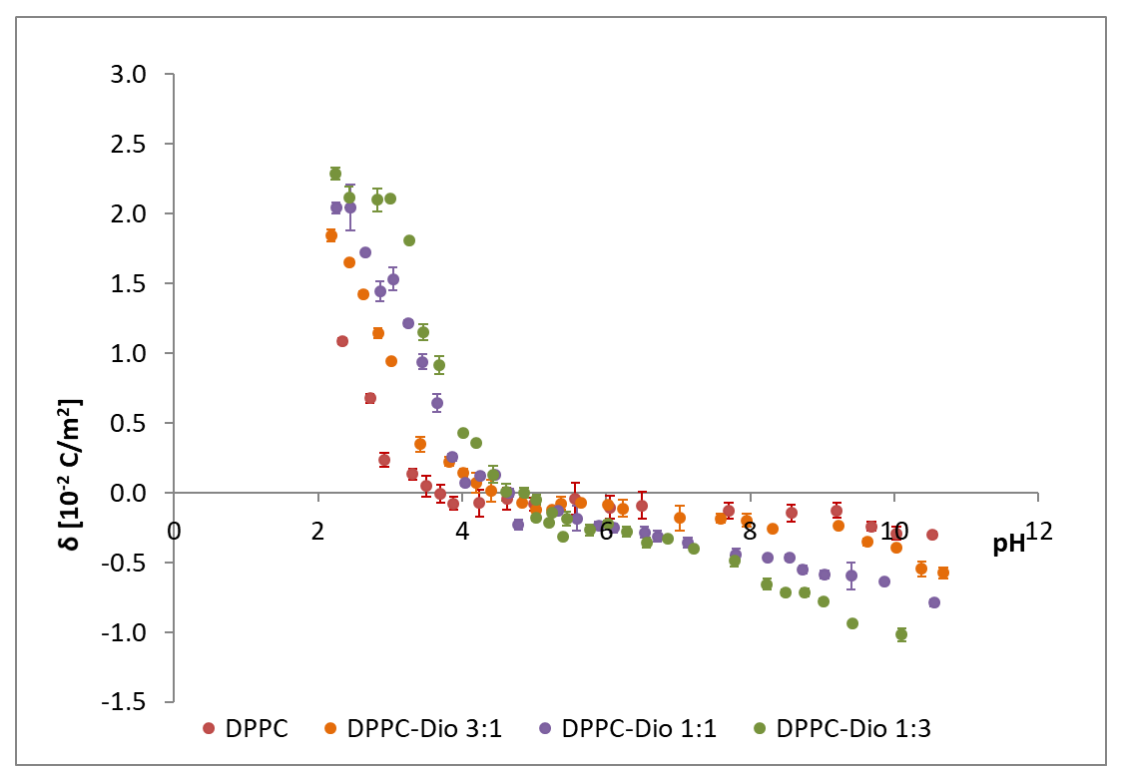

Figure 8. Dependence of DPPC and DPPC: the Dio membrane surface charge densities vs. the pH of the electrolyte solution. 


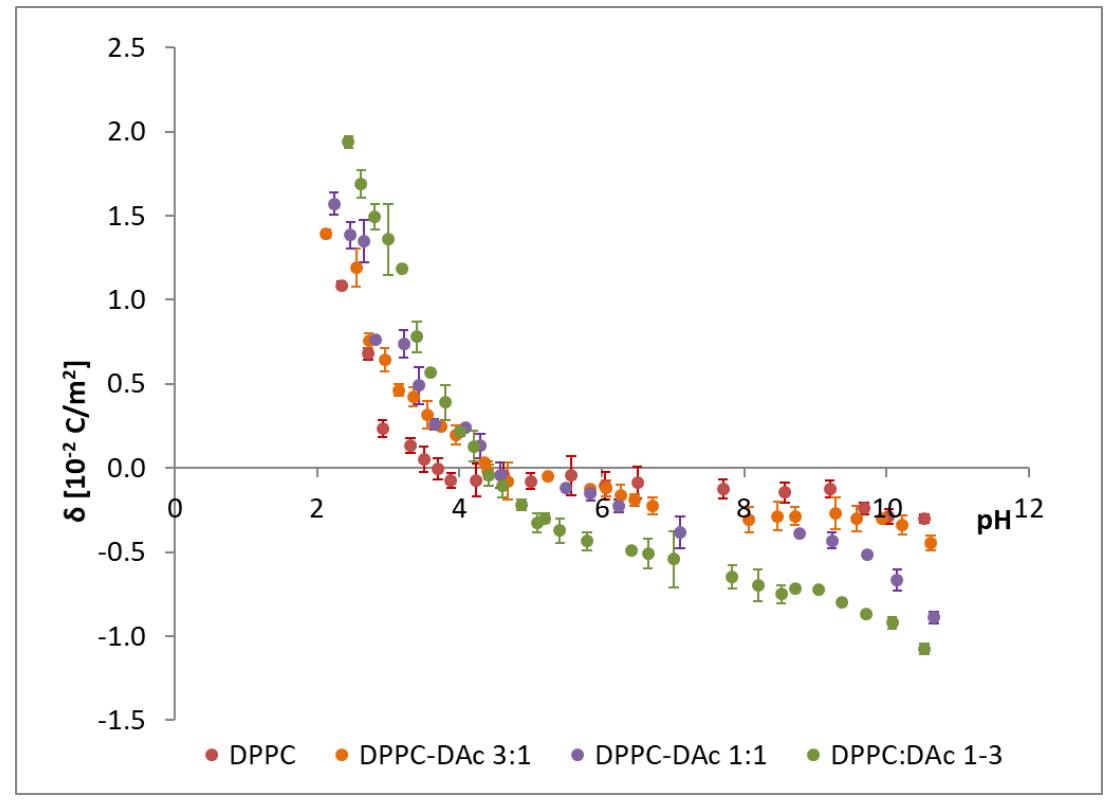

Figure 9. Dependence of DPPC and DPPC: the DAc membrane surface charge densities vs. the pH of the electrolyte solution.

Figure 8 presents the influence of the liposome composition and $\mathrm{pH}$ value on the DPPC-diosgenin bilayer surface charge densities. Additionally, in the figure, the data obtained for pure DPPC membranes are illustrated. The increase in the positive surface charge and increase of the negative surface charge with increasing diosgenin content in the DPPC membrane is observed. The isoelectric point of the membrane shows a shift towards higher $\mathrm{pH}$ values with increasing content of diosgenin in the DPPC membrane (from $\mathrm{pH} \sim 4$ for pure DPPC to $\mathrm{pH} \sim 5$ for the DPPC-Dio 1:3 system). Similar behavior was observed for the DPPC-DAc system (Figure 9).

Tables 3 and 4 summarize the results regarding the effect of the liposomal membrane composition on the value of the isoelectric point and surface charge density for the DPPC-Dio and DPPC-DAc systems, respectively.

Table 3. Membrane surface charge densities and isoelectric points for the DPPC-Dio system.

\begin{tabular}{cccc}
\hline \multirow{2}{*}{ Examined System } & Isoelectric Point & \multicolumn{2}{c}{$\begin{array}{c}\text { Surface Charge Density } \\
\boldsymbol{\delta}\left[\mathbf{1 0}^{-\mathbf{2}} \mathbf{C} \cdot \mathbf{m}^{\mathbf{2}}\right]\end{array}$} \\
\cline { 3 - 4 } & & Low $\mathbf{~ p H}$ Values & High pH Values \\
\cline { 3 - 4 } & 3.70 & $1.09 \pm 0.05$ & $-0.30 \pm 0.02$ \\
DPPC & 4.20 & $1.84 \pm 0.04$ & $-0.57 \pm 0.06$ \\
DPPC-Dio (3:1) & 4.30 & $2.04 \pm 0.05$ & $-0.79 \pm 0.02$ \\
DPPC-Dio (1:1) & 4.60 & $2.29 \pm 0.04$ & $-1.02 \pm 0.06$ \\
DPPC-Dio (1:3) & &
\end{tabular}

Table 4. Membrane surface charge densities and isoelectric points for the DPPC-DAc system.

\begin{tabular}{|c|c|c|c|}
\hline \multirow[t]{2}{*}{ System } & \multirow[t]{2}{*}{ Isoelectric Point } & \multicolumn{2}{|c|}{$\begin{array}{c}\text { Surface Charge Density } \\
\qquad \delta\left[10^{-2} \mathrm{C} \cdot \mathrm{m}^{-2}\right]\end{array}$} \\
\hline & & Low $\mathrm{pH}$ Values & High pH Values \\
\hline DPPC & 3.70 & $1.09 \pm 0.03$ & $-0.30 \pm 0.02$ \\
\hline DPPC-DAc (3:1) & 4.10 & $1.39 \pm 0.01$ & $-0.45 \pm 0.06$ \\
\hline DPPC-DAc (1:1) & 4.20 & $1.57 \pm 0.10$ & $-0.89 \pm 0.03$ \\
\hline DPPC-DAc (1:3) & 4.30 & $1.94 \pm 0.01$ & $-1.07 \pm 0.02$ \\
\hline
\end{tabular}


Modifying DPPC membranes with both diosgenin and diosgenin acetate causes changes in the surface charge density (Figures 8 and 9 and Tables 3 and 4), which is the parameter controlling phenomena in natural cell membranes, and affects host-pathogen interactions or membrane-bound enzymes. The membrane surface charge depends on the concentration and type of electrolyte used in measurements, but also on $\mathrm{pH}$ and membrane composition. Changes in membrane surface charge densities values are caused by $\mathrm{pH}$ changes; towards more negative values in high $\mathrm{pH}$ or towards more positive values in low $\mathrm{pH}$.

It is believed that the interaction of sapogenins with biological membranes may play a key role in their therapeutic activity. Therefore, compounds of natural origin are the valuable starting material for new drugs. In this work, it has been shown that the modification of DPPC membranes with both diosgenin and diosgenin acetate causes changes in the analyzed parameters, characterizing model lipid membranes.

\section{Conclusions}

The results presented in this work relate to the physicochemical and electrical properties of phospholipids modified with selected sapogenins, indicating special interactions between the components of the membranes, as well as between the components and surrounding solution.

The surface charge density of DPPC liposomes depends strongly on the modification of their structures, found here by examining the sapogenins and $\mathrm{pH}$ values of the electrolyte solution. The shift of the isoelectric point was also observed. Here, in the course of the interfacial tension measurements, the obtained good compliance between theoretical and experimental data verified the assumption of a 1:1 complex in the lipid bilayer. The lack of variation between the theoretical and experimental points indicates that our theoretical model (Section 3.1) can sufficiently describe the interactions in DPPC-sapogenin membranes. The mathematically calculated and experimentally confirmed data collected here are important in the understanding of various phenomena in which lipid bilayers participate in.

Biochemical processes occurring within membranes influence the harmonious functioning of natural cells. The processes controlled in the organism can be significantly altered by different factors, for example, diseases, poisoning, and cancer transformation. Any changes in cell functioning translate into cell membrane functioning, that is, these changes influence the physicochemical properties of membranes, such as the surface charge or surface tension. Understanding the mechanisms underlying the interaction between the studied sapogenins and DPPC membranes is a complex task due to the numerous properties that characterize them. Considering this fact, we conducted our research with the idea that, in the future, obtained data may be essential for understanding sapogenins for the course of a lot of physicochemical and biochemical phenomena. We hope that such studies, in particular, a quantitative description of the phenomena occurring in biological membranes, will contribute to the possibility of using sapogenins as potential therapeutic agents.

Author Contributions: Conceptualization, A.D.P. and J.K.; methodology, A.D.P. and J.K.; formal analysis, E.S. and K.K.; investigation, E.S. and K.K.; writing-original draft preparation, A.D.P., J.K., E.S. and K.K.; writing一review and editing, A.D.P. and J.K.; supervision, A.D.P. All authors have read and agreed to the published version of the manuscript.

Funding: The Zetasizer Nano ZS apparatus was funded by the European Funds for Regional Development and the National Funds of Ministry of Science and Higher Education, as part of the Operational Program Development of Eastern Poland 2007-2013 [POPW.01.03.00-20-044/11].

Acknowledgments: Thank you very much Prof. Izabella Jastrzębska for the donation of one of the reagents used for experiment (diosgenin acetate).

Conflicts of Interest: The authors declare no conflict of interest. 


\section{References}

1. Haltia, T.; Freire, E. Forces and factors that contribute to the structural stability of membrane proteins. Biochim. Biophys. Acta 1995, 1228, 1-27. [CrossRef]

2. Nobre, T.M.; Pavinatto, F.J.; Caseli, L.; Barros-Timmons, A.; Dynarowicz-Łątka, P.; Oliveira, O.N., Jr. Interactions of bioactive molecules \& nanomaterials with Langmuir monolayers as cell membrane models. Thin Solid Films 2015, 593, 158-188.

3. Elderdfi, M.; Sikorski, A.F. Langmuir-monolayer methodologies for characterizing protein-lipid interactions. Chem. Phys. Lipids 2018, 212, 61-72. [CrossRef]

4. Mazur, F.; Bally, M.; Städler, B.; Chandrawati, R. Liposomes and lipid bilayers in biosensors. Adv. Colloids Interface Sci. 2017, 249, 88-99. [CrossRef]

5. Baoukina, S.; Rozmanov, D.; Tieleman, D.P. Composition fluctuations in lipid bilayers. Biophys. J. 2017, 113, 2750-2761. [CrossRef]

6. Chibowski, E.; Szczes, A. Zeta potential and surface charge of DPPC and DOPC liposomes in the presence of PLC enzyme. Adsorption 2016, 22, 755-765. [CrossRef]

7. Penkauskas, T.; Preta, G. Biological applications of tethered bilayer lipid membranes. Biochimie 2019, 157, 131-141. [CrossRef]

8. Lee, Y.; Choi, S.Q. Quantitative analysis for lipophilic drug transport through a model lipid membrane with membrane retention. Eur. J. Pharm. Sci. 2019, 134, 176-184. [CrossRef]

9. Nikoleli, G.P.; Nikolelis, D.P.; Siontorou, C.G.; Nikolelis, M.T.; Karapetis, S. The Application of lipid membranes in biosensing. Membranes 2018, 8, 108. [CrossRef]

10. Nikoleli, G.P.; Nikolelis, D.P.; Evtugyn, G.; Hianik, T. Advances in lipid film based biosensors. TrAC Trends Anal. Chem. 2016, 79, 210-221. [CrossRef]

11. Sparg, S.G.; Light, M.E.; van Staden, J. Biological activities and distribution of plant saponins. J. Ethnopharmacol. 2004, 94, 219-243. [CrossRef] [PubMed]

12. Tang, H.F.; Cheng, G.; Wu, J.; Chen, X.L.; Zhang, S.Y.; Wen, A.D.; Lin, H.W. Cytotoxic asterosaponins capable of promoting polymerization of tubulin from the starfish Culcita novaeguineae. J. Nat. Prod. 2009, 72, 284-289. [CrossRef] [PubMed]

13. Aboutalebi, R.; Monfared, A. Saponin terpenoids, A brief review of mechanisms of actions and anti-cancerous effects. Am. Chem. Sci. J. 2016, 12, 1-8. [CrossRef]

14. Xu, X.-H.; Li, T.; Vivienne Fong, C.M.; Chen, X.; Chen, X.-J.; Wang, Y.-T.; Huang, M.-Q.; Lu, J.-J. Saponins from Chinese medicines as anticancer agents. Molecules 2016, 21, 1326. [CrossRef] [PubMed]

15. Tamura, Y.; Miyakoshi, M.; Yamamoto, M. Application of saponin-containing plants in foods and cosmetics. In Alternative Medicine; InTech: London, UK, 2012; pp. 85-101.

16. Sayyah, M.; Hadidi, N.; Kamalinejad, M. Analgesic and anti-inflammatory activity of Lactuca sativa seed extract in rats. J. Ethnopharmacol. 2004, 92, 325-329. [CrossRef]

17. Tatiya, A.U.; Desai, D.G.; Surana, S.J.; Patil, P.H. Anti-inflammatory and nitric oxide scavenging activity of roots of Eranthemum roseum. Indian Drugs. 2007, 44, 815-818.

18. Jain, A.S.; Surana, S.J.; Gokhale, S.B.; Tatiya, A.U.; Bothara, R.C. Antimicrobial properties of Eranthemum roseum (Vahl) R. Br. Iran J. Pharm. Res. 2007, 6, 131-133.

19. Soetan, K.O.; Oyekunle, M.A.; Aiyelaagbe, O.O.; Fafunso, M.A. Evaluation of the antimicrobial activity of saponins extract of Sorghum Bicolor L. Moench. Afr. J. Biotechnol. 2006, 5, 2405-2407.

20. Yang, C.-R.; Zhang, Y.; Melissa, R.; Khan, S.I.; Zhang, Y.-J.; Li, X.-C. Antifungal activity of C-27 steroidal saponins. Antimicrob. Agents Chemother. 2006, 50, 1710-1714. [CrossRef]

21. Yıldırım, I.; Kutlu, T. Anticancer agents: Saponin and tannin. Int. J. Biol. Chem. 2015, 9, 332-340. [CrossRef]

22. Bachran, C.; Bachran, S.; Sutherland, M.; Bachran, D.; Fuchs, H. Saponins in Tumor Therapy. Mini Rev. Med. Chem. 2008, 8, 575-584. [CrossRef] [PubMed]

23. Korchowiec, B.; Gorczyca, M.; Wojszko, K.; Janikowska, M.; Henry, M.; Rogalska, E. Impact of two different saponins on the organization of model lipid membranes. Biochim. Biophys. Acta 2015, 1848, 1963-1973. [CrossRef] [PubMed]

24. Jurek, I.; Górala, I.; Gęsiński, K.; Wojciechowski, K. Effect of saponins from quinoa on a skin-mimetic lipid monolayer containing cholesterol. Steroids 2019, 147, 52-57. [CrossRef] [PubMed] 
25. Orczyk, M.; Wojciechowski, K.; Brezesinski, G. The influence of steroidal and triterpenoid saponins on monolayer models of the outer leaflets of human erythrocytes, E. coli and S. cerevisiae cell membranes. J. Colloid Interf. Sci. 2020, 563, 207-217. [CrossRef]

26. Patel, K.; Gadewar, M.; Tahilyani, V.; Patel, D.K. A review on pharmacological and analytical aspects of diosgenin: A concise report. Nat. Prod. Bioprospect. 2012, 2, 46-52. [CrossRef]

27. Geisler, R.; Dargel, C.; Hellweg, T. The biosurfactant $\beta$-Aescin: A review on the physico-chemical properties and its interaction with lipid model membranes and Langmuir monolayers. Molecules 2020, 25, 117. [CrossRef]

28. He, Z.; Chen, H.; Li, G.; Zhu, H.; Gao, Y.; Zhang, L.; Sun, J. Diosgenin inhibits the migration of human breast cancer MDA-MB-231 cells by suppressing Vav2 activity. Phytomedicine 2014, 21, 871-876. [CrossRef]

29. Moalic, S.; Liagre, B.; Corbiere, C.; Bianchi, A.; Dauca, M.; Bordji, K.; Beneytout, J.L. A plant steroid, diosgenin, induces apoptosis, cell cycle arrest and COX activity in osteosarcoma cells. FEBS Lett. 2001, 506, 225-230. [CrossRef]

30. Petelska, A.D.; Naumowicz, M.; Figaszewski, Z.A. The interfacial tension of the lipid membrane formed from lipid-cholesterol and lipid-lipid systems. Cell Biochem. Biophys. 2006, 44, 205-212. [CrossRef]

31. Kotyńska, J.; Figaszewski, Z.A. Microelectrophoretic investigation of the interactions between liposomal membranes formed from a phosphatidylcholine- phosphatidylglycerol mixture and monovalent ions. Eur. Phys. J. E 2014, 37, 92. [CrossRef]

32. Kotyńska, J.; Figaszewski, Z.A. Adsorption of monovalent ions to phosphatidylcholine- cardiolipin membranes. Soft Mater. 2015, 13, 183-187. [CrossRef]

33. Petelska, A.D.; Figaszewski, Z.A. The equilibria of sphingolipid-cholesterol and sphingolipid-sphingolipid in monolayers at the air/water interface. J. Membrane Biol. 2013, 246, 13-19. [CrossRef]

34. Janicka, K.; Szeremeta, M.; Petelska, A.D. Equilibrium of phosphatidylcholine-ergosterol in monolayers at the air-water interface. J. Chem. Thermodyn. 2019, 138, 28-33. [CrossRef]

35. Petelska, A.D.; Figaszewski, Z.A. Interfacial tension of the lipid membrane formed fromphosphatidylcholinedecanoic acid and phosphatidylcholine-decylamine systems. J. Membrane Biol. 2011, 241, 103-108. [CrossRef]

36. Petelska, A.D.; Naumowicz, M.; Figaszewski, Z.A. Interfacial tension of the lipid membrane formed from lipid-fatty acid and lipid-amine systems. Bioelectrochemistry 2007, 70, 28-32. [CrossRef]

37. Kotyńska, J.; Dobrzyńska, I.; Figaszewski, Z.A. Effect of monovalent ion adsorption on the electric charge of phosphatidylcholine-Decylamine liposomal membranes. J. Bioenerg. Biomembr. 2008, 40, 637-641. [CrossRef]

38. Adamson, A.W.; Gast, A.P. Physical Chemistry of Surfaces, 6th ed.; A Wiley-Interscience Publication: New York, NY, USA, 1997.

39. Petelska, A.D.; Figaszewski, Z.A. Interfacial tension of the two-component bilayer lipid membrane modelling of cell membrane. Bioelectrochem. Bioenerg. 1998, 46, 199-204. [CrossRef]

40. Petelska, A.D.; Figaszewski, Z.A. Effect of $\mathrm{pH}$ on the interfacial tension of lipid bilayer membrane. Biophys. J. 2000, 78, 812-817. [CrossRef]

41. Petelska, A.D. Interfacial tension of bilayer lipid membranes. Cent. Eur. J. Chem. 2012, 10, 16-26. [CrossRef]

42. Tien, H.T.; Ottova-Leitmannova, A. Planar Lipid Bilayers (BLM's) and Their Applications Advanced in Planar Lipid Bilayers and Lipposomes; Elsevier: Amsterdam, The Netherlands, 2003.

43. Alexander, A.E.; Johnson, P. Colloid Science; Clarendon Press: Oxford, UK, 1949; pp. 30-79.

44. Inczedy, J. Analytical Applications of Complex Equilibria; Wiley: New York, NY, USA, 1976.

45. Petelska, A.D.; Naumowicz, M.; Figaszewski, Z.A. Physicochemical insights into equilibria in bilayer lipid membranes. In Advances in Planar Lipid Bilayers and Liposomes; Tien, H.T., Ottova, A., Eds.; Elsevier: Amsterdam, The Netherlands, 2006; Volume 3, pp. 125-187.

46. Sędek, Ł.; Michalik, M. New research on saponins shows their wide range of pharmacological activities. Kosmos 2005, 54, 345-356.

47. Janicka, K.; Jastrzebska, I.; Petelska, A.D. The equilibria of diosgenin-phosphatidylcholine and diosgenin-cholesterol in monolayers at the air/water interface. J. Membrane Biol. 2016, 249, 585-590. [CrossRef]

48. Janicka, K.; Jastrzebska, I.; Petelska, A.D. Complex formation equilibria between cholesterol and diosgenin analogues in monolayers determined by the Langmuir method. Biointerphases 2018, 13, 13-061001. [CrossRef] 
49. Gruen, D.W.R.; Wolfe, J. Lateral tensions and pressures in membranes and lipid monolayers. Biochim. Biophys. Acta 1982, 688, 572-580. [CrossRef]

50. Naumowicz, M.; Petelska, A.D.; Figaszewski, Z.A. Capacitance and resistance of the bilayer lipid membrane formed of phosphatidylcholine and cholesterol. Cell Mol. Biol. Lett. 2003, 8, 5-18.

51. Yermiyahu, U.; Nir, S.; Ben-Hayyim, G.; Kafkafi, U.; Scherer, G.F.E.; Kinraide, T.B. Surface properties of plasma membrane vesicles isolated from melon (Cucumus melo L.) root cells differing in salinity tolerance. Coll. Surf. B 1999, 14, 237-249. [CrossRef]

52. Camp, P.; Capitano, A.T. Size-dependent mobile surface charge model of cell electrophoresis. Biophys. Chem. 2005, 113, 115-122. [CrossRef]

(C) 2020 by the authors. Licensee MDPI, Basel, Switzerland. This article is an open access article distributed under the terms and conditions of the Creative Commons Attribution (CC BY) license (http://creativecommons.org/licenses/by/4.0/). 